\title{
HAEMOPHILIC BLOOD CYST
}

\section{Report of a Case}

\author{
D. M. Jones, Bristol, ENGLAND
}

A mongol boy of ten, a known haemophiliac, was seen in the orthopaedic department of Southmead Hospital in May 1962 with a swelling of the left foot. The parents were aware of a steady increase in size since the swelling was first noticed two months before. On examination, a cystic swelling was seen to occupy the forefoot, the skin on the dorsum being stretched over it and a dusky red in colour (Fig. 1). Radiographs showed destruction of the proximal two-thirds of the third metatarsal bone, an appearance consistent, it was thought, with destruction from within by an expanding lesion (Fig. 2). The diagnosis of a haemophilic blood cyst was made.

In spite of rest and splintage the cyst continued to enlarge. In a further two months the skin was on the point of bursting and the boy was in constant pain. As operation was unavoidable and as the unhealthy state of the skin prevented local dissection, the foot was removed by a modified Syme's amputation, the articular cartilage over the end of the tibia being retained. A pint of blood before operation and a further pint during operation, followed by 400 millilitres of fresh frozen plasma on the same day effectively controlled the immediate bleeding. Later clot formation delayed healing and a further seventeen transfusions of 400 millilitres of plasma were required before this was complete, eight weeks after operation. Histological examination confirmed a simple blood cyst.

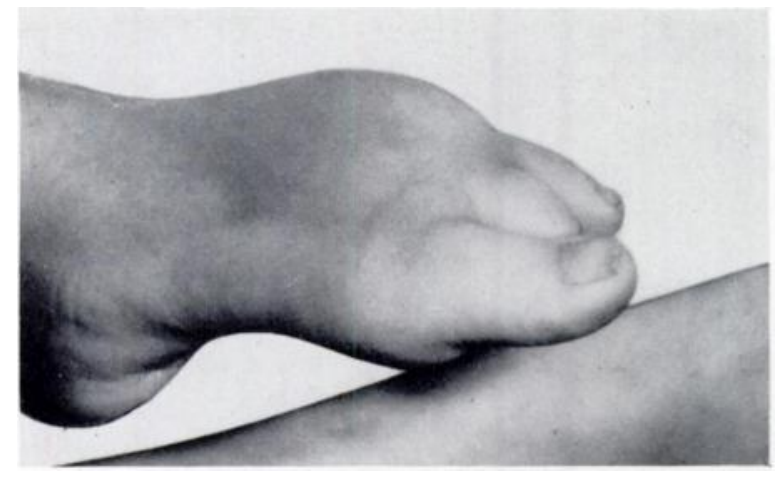

FIG. 1

FIGS. 1 AND 2

Figure 1-Photograph of the foot when first seen. Figure 2Radiograph showing destruction of the proximal two-thirds of the third metatarsal bone.

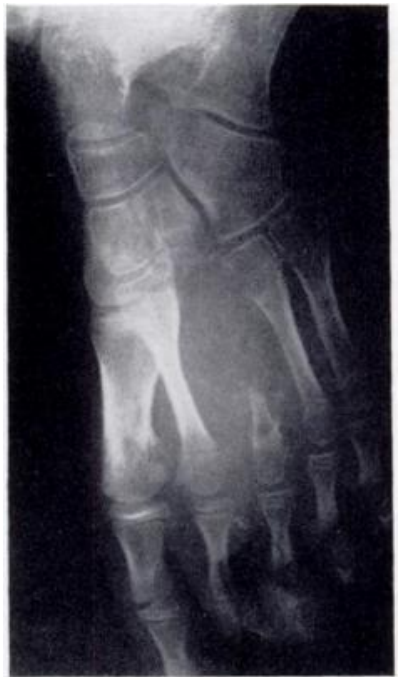

FIG. 2

During 1963 the boy walked for short spells, sometimes on the unprotected stump, at other times wearing a prosthesis. He continued in this manner until September 1963 when he was readmitted to hospital with a large haematoma of ten days' duration at the end of the stump. This haematoma showed a tendency to increase in size. It was aspirated under cover of one pint of blood followed by seven transfusions of 400 millilitres of plasma in five days, but it continued to enlarge. The needle track also leaked continuously. Eleven days later the stump was reamputated through the thin part of the leg immediately above the ankle. Bleeding was controlled at operation with one pint of blood, 400 millilitres of fresh frozen plasma and 100 millilitres of concentrated anti-haemophilic globulin (human variety). Clots 
again delayed healing, but this was complete after five weeks. After operation a further 100 millilitres of the concentrated human globulin and twenty transfusions of 400 millilitres of plasma were administered.

\section{DISCUSSION}

The cystic haematomas or blood cysts occasionally found in haemophilia and Christmas disease are fortunately rare. Hall, Handley and Webster in 1962 were able to discover no more than twenty-four cases in the literature. The cysts, it is believed, are the result of haemorrhages into the soft tissues and bones, particularly haemorrhages between the muscles, and they have acquired a sinister reputation from a tendency to progressive and uncontrollable expansion. The thigh is the commonest site and of nineteen cases referred to by Abell and Bailey (1960) twelve involved the thigh and only three the upper limbs, a distribution perhaps reflecting the role of weight-bearing stresses and strains in initiating the process.

Injuries to existing cysts are highly dangerous, some of the published case histories describing alarming increase in size following blows and similar incidents. The largest cysts are usually found in the thigh and flank, capacious regions capable of masking a progressive enlargement over many years. Burrowing among the muscles the cysts grow into complicated structures, their ramifications and "loculi" filled with partially clotted blood. The firm, even hard, outlines of these deeply placed swellings together with a curious radiographic appearance of the neighbouring bones have led to confusion with sarcomas, hence the term "pseudotumour" sometimes used when referring to the condition (Abell and Bailey 1960).

In the past the mortality from operation has been high, no less than fifteen of the twentyfour cases mentioned by Hall et al. in 1962 dying of complications after operation. Breakdown of the wound with haemorrhage and infection are the almost inevitable results of inadequate excision and biopsy. Infection is a special hazard; even aspiration is not free of risk and is best avoided. Of recent years, however, progress in the treatment of haemophilia (MacFarlane, Mallam, Witts, Bidwell, Biggs, Fraenkel, Honey and Taylor 1957) has considerably improved the opportunities for surgery, enabling extensive procedures to be performed with a reasonable chance of success (Egeberg, Borchgrevink and Hjort 1960; Hall et al. 1962).

There appear to be few if any unequivocal examples of a blood cyst beginning within the shaft of a bone. Ghormley and Clegg (1948) described a cystic appearance in an olecranon process; also the case of a boy of nineteen with an area of destruction in the shaft of the femur due to an old haemorrhage, but neither of these lesions showed any tendency to progressive expansion. The same authors also included the case of a man of fifty-two with a cystic area, very suggestive in appearance, in the shaft of the femur, but here again the condition could have begun outside the bone. The bone changes not uncommonly found in long-standing blood cysts are in most cases the result of prolonged external pressure. It is believed that the blood cyst described here began within the shaft of a metatarsal bone and, as such, affords an unusual example of a rare condition.

I am indebted to Dr G. H. Tovey and Dr N. F. Bruton for their advice in the management of this case. It is also a pleasure to thank a number of paediatric house officers for their patience in supervising a large number of difficult transfusions.

\section{REFERENCES}

Abell, J. M., Jun., and Bailey, R. W. (1960): Hemophilic Pseudotumor. Archives of Surgery, 81, 569.

Egeberg, O., Borchgrevink, C. F., and HJort, P. F. (1960): Use of Animal Antihaemophilic Globulin in Surgery: Exarticulation of the Hip in a Haemophiliac. Acta Medica Scandinavica, 167, 415.

Ghormley, R. K., and ClegG, R. S. (1948): Bone and Joint Changes in Hemophilia. Journal of Bone and Joint Surgery, 30-A, 589.

Hall, M. R. P., Handeey, D. A., and Webster, C. U. (1962): The Surgical Treatment of Haemophilic Blood Cysts. Journal of Bone and Joint Surgery, 44-B, 781.

MacFarlane, R. G., Mallam, P. C., Witts, L. J., Bidwell, E., Biggs, R., Fraenkel, G. J., Honey, G. E., and TAYLOR, K. B. (1957): Surgery in Haemophilia. The Use of Animal Antihaemophilic Globulin and Human Plasma in Thirteen Cases. Lancet, ii, 251.

VOL. 47 B, NO. 2, MAY 1965 